\title{
Assessing the toxic effects of hydroalcoholic extract of Stachys lavandulifolia Vahl on rat's liver
}

\author{
Taghikhani A, Afrough H, Ansari-Samani R, Shahinfard N, Rafieian-Kopaei M \\ Medical Plants Research Center, Shahrekord University of Medical Sciences, Shahrekord, Iran. \\ rafieian@yahoo.com
}

\begin{abstract}
Aims: Stachys lavandulifolia Vahl is a frequently used plant to treat different diseases, but its probable toxic effects have not been reported yet. This study aimed to study the toxicity of the extract on rats' liver. Methods: In this experimental study, 100 rats were designated into 10 groups and injected normal saline or Stachys lavandulifolia Vahl extract at 50,100,150, and $200 \mathrm{mg} / \mathrm{kg}$, intraperitoneally for 28 days. Four case groups and one control group were examined for ALT, AST and ALP after one month and the other groups were evaluated after two months. Results: In the first month, the increase of ALP at all doses and the increase of AST at $200 \mathrm{mg} / \mathrm{kg}$ was significant, compared to the control group $(p<0.05)$. In the second month, AST increased at the dosage of $150 \mathrm{mg} /$ $\mathrm{kg}$, and ALP decreased at the dosage of $100 \mathrm{mg} / \mathrm{kg}$, compared to the control group $(p<0.05)$. Histopathological assessment showed a significant dose dependent increase both in necrotic-inflammatory reactions and fibrotic lesions, in the first and second months, compared to the control group $(p<0.001)$.

Conclusions: The Stachys lavandulifolia extract injected intraperitoneally has hepatotoxic effect, which is not eliminated by the drug withdrawal. Therefore, it is necessary to be consumed with caution (Tab. 4, Fig. 1, Ref. 21). Text in PDF www.elis.sk.

Key words: animal, drug toxicity, toxicity, herb.
\end{abstract}

Liver is one of the most important organs for absorption, metabolism and excretion of drugs and other harmful substances. Therefore, it is subject to toxic effects of the drugs and different substances.

Several biochemical tests are used to diagnose the liver diseases. The most important of these tests are serum aminotransferases (ALT, AST) that are indicators of hepatocyte damage. Increasing of their activities usually indicate the presence of an active liver disease. Alkaline phosphatase (ALP) is increased in diseases related to the secretion and excretion of bile (cholestatic diseases) (1).

Medicinal plants play a central role as traditional medicine for their therapeutic or preventive effects against drug or chemical toxicities (2-5), however, some herbs, which even have been used traditionally might have acute or chronic toxicity. Among the plants that might have liver toxicity based on the traditional beliefs of people in Chaharmahal and Bakhtiari (a province in Iran), is Stachys lavandulifolia (1). This plant is from the family of Laminacea, which is known as Betony in English (Wooly Betony, Lamb's ear, Woundwort or Oulileh, in Persian) (6-8). The active components of this plant include phenylethanoids, terpenoids and flavonoids (7).

Medical Plants Research Center, Shahrekord University of Medical Sciences, Shahrekord, Iran

Address for correspondence: M. Rafieian-Kopaei, Medical Plants Research Center, Shahrekord University of Medical Sciences, Shahrekord, Iran Phone: +98.9131811842, Fax: +98.3330709

Acknowledgements: This manuscript is derived from MD dissertation of H. Afrough. Authors would like to highly appreciate the Research Deputy of Shahrekord University of Medical Sciences, due to funding. Moreover, the personnel of the Medical Plants Research Center of this University are appreciated due to their cooperation in this project.
This plant is a stomach tonic (1) and is taken to treat infections, asthma and rheumatic diseases (9). Betony has anxiolytic effects (1) and is useful in the treatment of genital tumors, skin cancer and inflammation (7). The anti-microbial effects of this plant against Streptococcus sanguis are also recognized. The extract of this plant has shown to have analgesic and anti-inflammatory activities in dosages of 50-200 mg/kg (11).

In the study, the extract of this plant had not have any effect on embryonic development and had not caused any abnormalities in rat (12), yet in another study, it was shown to induce abortion (13).

Regarding the fact that Stachys lavandulifolia Vahl is frequently used to treat different diseases and its liver toxicity has not been examined in users yet, this study aimed to evaluate the probable toxicity of this extract on rat's liver.

\section{Materials and methods}

\section{Extraction Method}

In this study, the aerial parts of Stachys lavandulifolia Vahl were collected from Hafshejan, a city in Chaharmahal and Bakhtiari province of Iran. A specimen was deposited in the herbarium unit of the Medical Plants Research Center of Shahrekord University of Medical Sciences, after being authenticated by the botanist expert (herbarium no. 204). After passing the drying process in shadow at $37^{\circ}$ centigrade, the extracting process was carried out by maceration method using $80 \%$ ethanol. In order to prepare the extract, $500 \mathrm{cc}$ of $80 \%$ ethanol was poured on 100 grams of the plant powder and was filtered after 72 hours. The obtained extract was transferred to the vacuum distillation apparatus (rotary) and 
concentrated to one third of the initial value. Then the extract was dried by oven at $40^{\circ}$ centigrade and four different concentrations were prepared for study.

\section{Standardization of the extract}

To standardize Stachys lavandulifolia extract, its total phenolic and flavonoid components were measured as follows:

The phenolic compounds were measured equivalent to gallic acid using Folin-Ciocalteu colorimetry as previously described by Shirzad and coworkers (14), with some modifications. Different concentrations of standard gallic acid $(12.5,25,50,62.5,100$ and $125 \mathrm{ppm}$ in methanol $60 \%$ ) were prepared. Then, $0.1 \mathrm{ml}$ from each sample was transferred into a test tube and $0.5 \mathrm{ml}$ Folin-Ciocalteu $10 \%$ was added as reactive agent. The solutions were left for 8 minutes at a room temperature and then $0.4 \mathrm{ml}$ sodium carbonate $7.5 \%$ was added. The tubes were maintained for $30 \mathrm{~min}$ at the laboratory temperature and then assayed in three intervals by a spectrophotometer (Unico uv 2010) at $765 \mathrm{~nm}$ wavelength. To measure the overall phenol in the extracts, $0.01-0.02 \mathrm{~g}$ of the extracts was dissolved in $60 \%$ methanol, reaching $10 \mathrm{ml}$ and then, the overall level of phenol was measured. However, instead of using the standard solution, $0.1 \mathrm{ml}$ extract solution was added. Finally, the overall phenol level was obtained from the read optical density in $\mathrm{mg} / \mathrm{g}$ extract in gallic acid equivalent.

Total flavonoids were measured equivalent to Rutin, using Chloride aluminum colorimetry and Rutin methods, as previously described by Kazemi and coworkers (15), with a slight modification. First, different concentrations of standard "Rutin" (25, 50, 100,250 and $500 \mathrm{ppm}$ ) were prepared in methanol $60 \%$. Then, from each solution, a $\mathrm{ml}$ was transferred into test tubes and mixed with $1 \mathrm{ml}$ of chloride aluminum $2 \%$. Afterwards, $6 \mathrm{ml}$ potassium acetate $5 \%$ was added and the optical density level was read after 40 minutes at $415 \mathrm{~nm}$ wavelength. The concentration levels of the standard solutions were assayed in three intervals. In order to measure the overall level of flavonoids in the extracts, $0.01-0.02$ $\mathrm{g}$ of the extracts was dissolved in methanol $60 \%$, reaching 10 $\mathrm{ml}$. Then, using chloride aluminum colorimetry, the total level of flavonoids was measured. However, instead of using the standard solution, $1 \mathrm{ml}$ of the extract was added. The total flavonoid level was calculated in mg per one gram extract, equivalent to Rutin.

The total flavonol was also measured using chloride aluminum colorimetry and Rutin procedure, however, the optical density level reading, was obtained after 2.5 hours at $440 \mathrm{~nm}$ wavelength (16).

\section{Interventional procedure}

In this experimental study, 100 rats at 8-12 weeks of age, weighing approximately 250 grams were placed randomly in 10 groups of 10 members, including 2 control and 8 case groups. The animals were kept at $22-25^{\circ} \mathrm{C}$ in normal condition (darkness and light) and normal feeding.

The herbal extract was injected intraperitoneally for one month, at the dosages of $50,100,150$, and $200 \mathrm{mg} / \mathrm{kg}$ to the 8 case groups (each concentration was injected to two groups). During this period of time, $0.3 \mathrm{ml}$ of normal saline was injected to each rat of the two control groups. At the end of the first month, samples were taken from 4 case groups and one control group, considering medical ethics and under general anesthesia. Moreover, at the end of the second month, specimens were taken from the other groups to measure the levels of liver enzymes including Alanine Aminotransferase (ALT), Aspartate Aminotransferase (AST) and Alkaline Phosphatase (ALP) in order to analyze the effect of time on the improvement of the plant resulted complications. Histopathological tests were done on samples through autopsy and taking liver samples.

Knodell-Ishak scoring system was used in this study in order to measure the amount of inflammation and fibrosis in the liver tissue (17).

The data were described by the mean and standard deviation (SD) by SPSS 11.5 software and were analyzed using ANOVA, Scheffe, Kruskal-Wallis, Dunn and Mann-Whitney tests.

\section{Results}

Total flavonoid, flavonol and phenolic contents of Stachys Lavandulifolia Vahl

The total phenolic content of Stachys Lavandulifolia Vahl was $443.3 \pm 8.1 \mathrm{mg}$ gallic acid equivalent/g, its total flavonoid content was $176 \pm 2.9 \mathrm{mg}$ Rutin equivalent/g, and the total flavonol content was $132.7 \pm 13.1 \mathrm{mg}$ Rutin equivalent/g dry extract.

\section{Effect of the extract on rats'liver enzymes}

Effect of the extract on rats' liver enzymes in the first month is presented in Table 1. There was a significant difference in the mean of ALT levels at all doses and AST at the dose of $200 \mathrm{mg} /$ $\mathrm{kg}$ in comparison with the control group. No significant difference was observed in any of the case groups regarding the change in liver enzymes $(\mathrm{p}>0.05)$.

The effect of Stachys lavandulifolia Vahl hydro-alcoholic extract on liver enzymes in the second month is presented in Table 2. In the second month, the mean of ALT and AST had a significant difference at doses 50,150, and $200 \mathrm{mg}$ in comparison with the control group. None of the groups had significant difference

Tab. 1. Effect of Stachys lavandulifolia Vahl hydro-alcoholic extract on rats' liver enzymes in the first month.

\begin{tabular}{lccc}
\hline \multirow{2}{*}{ Groups } & \multicolumn{3}{c}{ Mean \pm SD } \\
\cline { 2 - 4 } & AST & ALT & ALP \\
\hline Control & $151.60 \pm 94.21$ & $92.00 \pm 64.37$ & $125.40 \pm 49.89$ \\
$50 \mathrm{mg} / \mathrm{kg}$ & $236.10 \pm 196.84$ & $101.30 \pm 52.35$ & $* * 723.70 \pm 195.95$ \\
$100 \mathrm{mg} / \mathrm{kg}$ & $386.90 \pm 275.2$ & $131.30 \pm 79.13$ & $* * 621.80 \pm 144.73$ \\
$150 \mathrm{mg} / \mathrm{kg}$ & $306.80 \pm 346.26$ & $174.70 \pm 142.19$ & $* * 729.40 \pm 221.88$ \\
$200 \mathrm{mg} / \mathrm{kg}$ & $* 508.10 \pm 156.99$ & $180.80 \pm 99.44$ & $* * 554.60 \pm 188.28$ \\
\hline$* * \mathrm{p}<0.001, * \mathrm{p}<0.05$, in comparison with the control group $(\mathrm{n}=10)$
\end{tabular}

Tab. 2. Effect of Stachys lavandulifolia Vahl hydro-alcoholic extract on rats' liver enzymes at the end of the second month.

\begin{tabular}{lccc}
\hline \multirow{2}{*}{ Groups } & \multicolumn{3}{c}{ Mean \pm SD } \\
\cline { 2 - 4 } & AST & ALT & ALP \\
\hline Control & $162.30 \pm 84.79$ & $96.00 \pm 53.25$ & $131.50 \pm 54.17$ \\
$50 \mathrm{mg} / \mathrm{kg}$ & $* 334.00 \pm 136.82$ & $181.50 \pm 186.97$ & $* 323.50 \pm 133.94$ \\
$100 \mathrm{mg} / \mathrm{kg}$ & $185.60 \pm 135.08$ & $147.10 \pm 109.09$ & $232.80 \pm 111.99$ \\
$150 \mathrm{mg} / \mathrm{kg}$ & $* 347.50 \pm 179.66$ & $210.90 \pm 229.21$ & $* * 418.60 \pm 136.45$ \\
$200 \mathrm{mg} / \mathrm{kg}$ & $* 360.10 \pm 93.26$ & $82.60 \pm 19.14$ & $* * 414.30 \pm 182.20$ \\
\hline$* \mathrm{p}<0.001, * \mathrm{p}<0.05$, in comparison with the control group $(\mathrm{n}=10)$
\end{tabular}


Tab. 3. Comparing the effect of Stachys lavandulifolia Vahl hydro-alcoholic extract on rats' liver enzymes between the first and the second month.

\begin{tabular}{|c|c|c|c|c|c|c|}
\hline \multirow{2}{*}{ Variable } & \multirow{2}{*}{$\begin{array}{l}\text { Group } \\
\text { Month }\end{array}$} & \multicolumn{5}{|c|}{ Mean \pm SD } \\
\hline & & Control & Dose 50 & Dose 100 & Dose 150 & Dose 200 \\
\hline \multirow{2}{*}{$\mathrm{AST}$} & First & $151.60 \pm 94.21$ & $236.10 \pm 196.84$ & $386.90 \pm 275.2$ & $306.80 \pm 346.26$ & $508.10 \pm 156.99$ \\
\hline & Second & $162.30 \pm 84.79$ & $334.00 \pm 136.82$ & $185.60 * \pm 135.08$ & $347.50 \pm 179.66$ & $* 360.10 \pm 93.26$ \\
\hline \multirow{2}{*}{ ALT } & First & $92.00 \pm 64.37$ & $101.30 \pm 52.35$ & $131.30 \pm 79.13$ & $174.70 \pm 142.19$ & $180.80 \pm 99.44$ \\
\hline & Second & $96.00 \pm 53.25$ & $181.50 \pm 186.97$ & $147.10 \pm 109.09$ & $210.90 \pm 229.21$ & $* * 82.60 \pm 19.14$ \\
\hline \multirow[b]{2}{*}{ ALP } & First & $125.40 \pm 49.89$ & $723.70 \pm 195.95$ & $621.80 \pm 144.73$ & $729.40 \pm 221.88$ & $554.60 \pm 188.28$ \\
\hline & Second & $131.50 \pm 54.17$ & $* * * 323.50 \pm 1333.94$ & $* * * 232.80 \pm 111.99$ & $* * * 418.60 \pm 136.45$ & $414.30 \pm 182.20$ \\
\hline
\end{tabular}

${ }^{*} \mathrm{p}<0.05, * * \mathrm{p}<0.01, * * * \mathrm{p}<0.001$ in comparison with the first month, $(\mathrm{n}=10)$

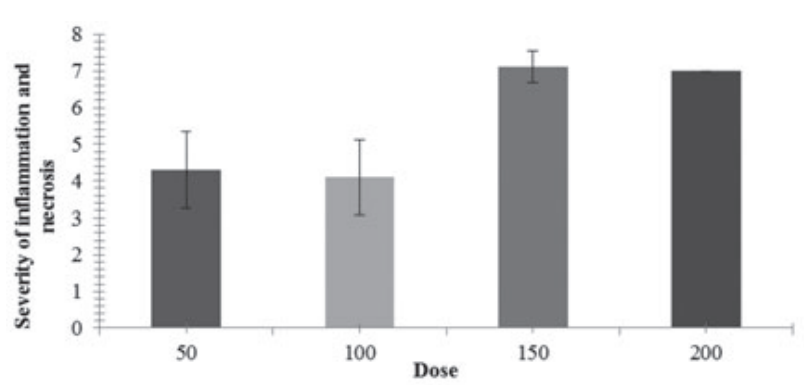

Fig. 1. Comparing the severity of inflammation and necrosis in rats receiving four different doses $(50,100,150$ and $200 \mathrm{mg} / \mathrm{kg})$ of Stachys lavandulifolia Vahl extract in the first month. Numbers are based on Mean \pm SEM (the maximum point for the inflammation and necrosis=18).

regarding liver enzymes ( $>00.05$ ), except for the dose of $150 \mathrm{mg} /$ $\mathrm{kg}$ that had a significant difference regarding ALP compared to the dose of $100 \mathrm{mg} / \mathrm{kg}(\mathrm{p}<0.05)$. Comparison results of the first and second month of each of the four doses, regarding the liver enzymes, are presented in Table 3.

\section{Histopathological results}

Histopathological assessment of rats' liver tissue showed no considerable pathological differences in the control group. Histopathological assessment of liver tissue in rats, receiving the extract at four mentioned doses showed a significant difference both in necrotic-inflammatory reactions and fibrotic lesions, in the first and the second months using the Mann-Whitney test in comparison with the control group $(\mathrm{p}<0.001)$.

In the first month, there was a significant difference between the groups receiving the Stachys lavandulifolia Vahl extract with doses of 50 and 150; 50 and 200; 100 and 150; 100 and $200 \mathrm{mg} /$

Tab. 4. Comparing the means of necrotic-inflammatory responses and fibrotic lesions between the first and the second month in each of the four groups of rats receiving the extract.

\begin{tabular}{llcc}
\hline $\begin{array}{l}\text { Groups } \\
(\mathrm{mg} \backslash \mathrm{kg})\end{array}$ & Month & $\begin{array}{c}\text { Mean } \pm \text { SD } \\
\text { inflammatory responses }\end{array}$ & $\begin{array}{c}\text { Mean } \pm \text { SD } \\
\text { fibrotic lesions }\end{array}$ \\
\hline 50 & First & $4.3 \pm 3.3$ & $1.9 \pm 1.3$ \\
& Second & $5.4 \pm 1.8$ & $2.4 \pm 1.2$ \\
\hline 100 & First & $4.1 \pm 3.2$ & $2.4 \pm 0.51$ \\
& Second & $5.6 \pm 0.81$ & $* 3.00 \pm 0.00$ \\
\hline 150 & First & $7.1 \pm 1.2$ & $3.00 \pm 0.00$ \\
& Second & $6.4 \pm 0.69$ & $3.00 \pm 0.00$ \\
\hline 200 & First & $7.00 \pm 0.00$ & $3.00 \pm 0.00$ \\
& Second & $* 6.1 \pm 0.3$ & $3.00 \pm 0.00$ \\
\hline p $<0.05$ in comparison with the first month (Mann-Whitney test)
\end{tabular}

$\mathrm{p}<0.05$ in comparison with the first month (Mann-Whitney test) $\mathrm{kg}$, both in necrotic-inflammatory reactions and fibrotic lesions using Dunn's test $(\mathrm{p}<0.05)$ (Fig. 1). As it is clear in the diagram, a considerable difference was observed between the doses 50 or 100 and doses 150 and $200 \mathrm{mg} / \mathrm{kg}$.

In the second month, no significant differences were observed in necrotic-inflammatory reactions or fibrotic reactions in the four groups of rats ( $p>0.05)$ (Dunn's test).

The mean of necrotic-inflammatory reactions in the second month decreased in comparison with the first month in the group receiving the dose of $200 \mathrm{mg} / \mathrm{kg}$ of the extract. However, the mean of fibrotic lesions increased in the second month in comparison with the first month, in the group receiving the dose of $100 \mathrm{mg} / \mathrm{kg}$ of the extract $(\mathrm{p}<0.05)$ (Tab. 4).

\section{Discussion}

This study aimed to evaluate the toxicity of Stachys lavandulifolia Vahl extract on rats' liver.

A significant increase in ALP and AST was observed following Stachys lavandulifolia Vahl usage. Histopathological assessment also showed a significant dose dependent increase both in necrotic-inflammatory reactions and fibrotic lesions, in the first and the second month compared to the control group.

Few studies have been performed on the toxic effects of Stachys lavandulifolia Vahl. However, Stachys byzantina has been shown to have cytotoxic effects (18). Abortive effect of Stachys lavandulifolia Vahl has also been reported in in mice (13), but no report was found on the probable toxicity of Stachys lavandulifolia Vahl on the liver.

At the end of the first month, all groups, which received different doses of the extract, showed a considerable ALP increase in comparison with the control group. This increase was probably due to its toxic effect on bile duct cells or hepatocyte canalicular membrane (19). It can be concluded that the safe dosage of this drug should probably be under $50 \mathrm{mg} / \mathrm{kg}$ in this case.

At the end of the second month (i.e. one month after stopping the injection of the extract), ALP showed a considerable increase in comparison with the control group, at 50,150 , and $200 \mathrm{mg} / \mathrm{kg}$ doses (due to an unclear reason, the dose of $100 \mathrm{mg} / \mathrm{kg}$ was not significant in this regard). It means that even one month after the stopping the extract injection, its toxic effect on bile duct epithelial cells and hepatocyte canalicular membrane remained unchanged.

At the end of the first month, AST had a significant increase at the dose of $200 \mathrm{mg} / \mathrm{kg}$ (highest dose), in comparison with the control group. The relative increase of AST can imply the higher severity of fibrosis process in liver and this issue is consistent with 
$121-124$

the creation of widespread pathological lesions at this dose, which means that probably higher doses might start the fibrosis process in a shorter time. Therefore, it can be concluded that the extract of Stachys lavandulifolia Vahl can have toxic effects on parenchyma and liver cells at the dose of $200 \mathrm{mg} / \mathrm{kg}$.

Although, the increase of liver enzymes in the first month did not depend on increasing of the extract dose, referring to Table 1, one can find a relative linear relation between increasing of the liver enzymes and the dose.

AST, at the doses of 150 and $200 \mathrm{mg} / \mathrm{kg}$, but not at lower doses, was increased considerably in comparison with the control group, which indicates that this effect is dose dependent.

ALP, at the doses of 50,100 and $150 \mathrm{mg} / \mathrm{kg}$; ALT at the dose of $200 \mathrm{mg} / \mathrm{kg}$; AST at the doses of 100 , and $200 \mathrm{mg} / \mathrm{kg}$ were considerably decreased in the second month, in comparison with the first month. It means that withdrawal of the extract consumption has given an opportunity to liver to partially regenerate (although the toxic effect continues). In other words, partial improvement is observed and may be longer follow-up reveal their return to the normal range.

Regarding the results, a safe dose for lack of inflammatory and fibrotic reactions should be under $50 \mathrm{mg} / \mathrm{kg}$, because at the studied doses clear and significant inflammatory and fibrotic reactions were seen in comparison with the control group.

As the results showed, the difference was significant in the first month between doses 50 or $100 \mathrm{mg} / \mathrm{kg}$, and 150 or $200 \mathrm{mg} / \mathrm{kg}$, regarding the necrotic-inflammatory reactions or fibrotic lesions, which means the exacerbation level of these lesions started after $100 \mathrm{mg} / \mathrm{kg}$.

In the second month, the mean of necrotic-inflammatory and fibrotic reactions were significant in four groups of rats receiving the extract in comparison with the control group. It means that about one month after stopping the injection of the extract, its toxic effect continued at all the studied doses and had caused the continuity of necrotic-inflammatory and fibrotic responses.

The cytotoxic effects of savory or Satureja genus that belong to the Lamiaceae family, are known as the result of terpenoid and especially triterpene available in them (18). One of the active components of Stachys lavandulifolia Vahl is also terpenoid (7, 20,21). Therefore, possibly at least one of the factors that caused the toxic effect of the Stachys lavandulifolia Vahl extract in this study is its terpenoid combinations. Of course, it is possible that other factors caused the toxic effect of the extract. Anyway, further studies should be done to clarify the toxic reasons of the extract of Stachys lavandulifolia Vahl, especially its terpenoid components.

\section{Conclusion}

During this study, it was found that the extract of Stachys lavandulifolia Vahl was able to create toxic effects in rats at the studied doses; therefore, the following suggestions should be mentioned:

Patients with underlying liver diseases should take this drug more cautiously, especially at high doses.

Further studies should be done on less than $50 \mathrm{mg} / \mathrm{kg}$ doses in order to discover the determinant dosage for the hepatotoxicity onset.

Further research is suggested to discover the mechanism of toxic effects of this plant.

\section{References}

1. Reitman S, Frankel S. A colorimetric method for determination of serum glutamic oxaloacetic and glutamic pyruvic transaminase. Am J Clin Path 1957; 28: 59-63.

2. Ghorbani A, Ehsanpour A, Roshanzamir N, Omidvar B. Alterations in antibiotic susceptibility of urinary tract infection pathogens. J Nephropathol 2012; 1 (1): 43-48.

3. Kadkhodaee M. Erythropoietin; bright future and new hopes for an old drug. J Nephropathol 2012; 1 (2): 81-82.

4. Mohammadi Torbati P. Focal segmental glomerulosclerosis; collapsing variant. J Nephropathol 2012; 1 (2): 87-90.

5. Assadi F. The epidemic of pediatric chronic kidney disease the danger of skepticism. J Nephropathol 2012; 1 (2): 61-64.

6. Nasri H, Shirzad H. Toxicityn and safety of medicinal plants. J Herb Med Pharmacol 2013; 2 (2): 21-22.

7. Maleki N, Garjani A, Nazemiyeh H, Nilforoushan A, Eftekhar S, Allameh H. Potent anti - inflammatory activities of hydroalcholic extract from aerial parts of Stachys inflata on rat. J Ethnopharmacol 2001; 75 (2-3): 218-213.

8. Feizbakhsh A. composision of essential oil of Stachys lavandulifolia Vahl from Iran. J Essential Oil Res 2003; 11 (30): 112-120.

9. Babakhanlo P, Mirzai M, Sefidkon F, Ahmadi L, Barazaneh MM, Asgari F. Flor of Iran.1st ed. Tehran: Ministry of Jahad-e-Agriculture.1998; 82-64.

10. Rabbani M, Sajjadi SE, Jalali A. Hydroalcohol extract and fractions of Stachys lavandulifolia Vahl: effect on spontaneous motor activity and elevated plus-maze behaviour. Phytother Res 2005; 19 (10): 854-858.

11. Khanavi M, Sharifzadeh M, Hadjiakhoondi A, Shafiee A. Phytochemical investigation and anti inflammatory activity of aerial parts of Stachys byzanthina C. Koch. J Ethnopharmacol 2005; 97 (3): 463-468.

12. Kouchesfahani M, Parivar K. Surveying the effects of Hypericum perforatum on Balb/C mice. Med Sci J Islamic Azad Univ Tehran Med Branch 2006; 16 (2): 83-85.

13. Jafarzadeh L, Asgari A, Golshan-Iranpoor F, Kheiri S, Parvin N, Rafieian M, Taji F, Shahinfard N, Rahimian A, Azadegan-Dehkordi F. Abortificient effects of Stachys lavandulifolia Vahl in mice. J Shahrekord Univ Med Sci 2010; 2 (4): 26-31.

14. Shirzad H, Shahrani M, Rafieian-Kopaei M. Comparison of morphine and tramadol effects on phagocytic activity of mice peritoneal phagocytes in vivo. Int Immunopharmacol 2009; 9 (7-8): 968-970.

15. Kazemi S, Asgary S, Moshtaghian J, Rafieian M, Adelnia A, Shamsi F. Liver-protective effects of hydroalcoholic extract of Allium hirtifolium Boiss in rats with alloxan-induced diabetes mellitus. Arya Atherosclerosis 2010; 6 (1): 11-15.

16. Sharafati R, Sherafati F, Rafieian-Kopaei M. Biological characterization of Iranian walnut (Juglans regia) leaves. Turk J Biol 2011; 35: 635-639.

17. Braunwald K, Hauser F. Harrison's Principles of Internal Medicine, volume II, 16th Edition. 1845: 287-292.

18. Shrimp B. Cytotoxicity of some medicinal plants belongs to Lamiaceae, Asteracea, Rosaceae and Boraginaceae families. Gohari AR, Saeidnia S, Gohari MR, Moradi-Afrapoli F, Malmir M, Hadjiakhoondi A, Yazdanpanah M. J Med Plants 2009; 8 (29): 87-93.

19. Kumar AF, Robbins M. Basic pathology (Organ Systems), 8th Edition. Translated by Fatollahi A, Guran Urimi O. Arjmand Publication. 2008: 338.

20. Kartsev VG, Stepanichenko NN, Auelbekov SA. Chemical composition and pharmacological properties of plant of the genus Stachys. Chem Natur Compounds. 1994; 30: 645-654.

21. Skaltsa HD, Lazari DM, Chinou IB, Loukis AE. Compositon and antibacterial activity of the essential oils of Stachys candida and S. chrtsantha from southern Greece. Planta Med 1999; 65: 255-256.

Received July 26, 2012. Accepted October 27, 2013. 